\title{
A avaliação de ensino-aprendizagem e as políticas públicas estaduais: uma revisão teórico-prática
}

Resumo: $\mathrm{O}$ artigo é resultado da análise das propostas de avaliação dos documentos curriculares de ensino fundamental 2 na disciplina Inglês de seis estados brasileiros. Seu objetivo é discutir a relação entre as avaliações propostas e os objetos de ensino-aprendizagem expressos nesses documentos. Conclui-se que nos documentos, embora encontremos textos que afirmem seguir uma proposta sócio-histórico-cultural (com base em Vygotsky, 1926 a 1934), sua proposta de avaliação, via de regra, ainda não segue a mesma perspectiva. Verifica-se também que as instruções relativas à avaliação de ensino-aprendizagem não priorizam apenas as provas, incluindo a autoavaliação.

Palavras-chave: avaliação de ensino-aprendizagem, validade aparente, validade de construto, validade de conteúdo, teorias de ensino-aprendizagem. 


\section{INTRODUZINDO A PREOCUPAÇÃO COM A QUESTÃO DA AVALIAÇÃO}

A avaliação é uma das atividades mais antigas exercidas pelo ser humano; é, no entanto, uma atividade construída em um vir-a-ser contínuo e com pouco ou nenhum planejamento, já que, por vezes, pode ser realizada sem embasamento teórico, sem conhecimento do que seria avaliar, de como deveria ser exercida. Pensaríamos que, na área educacional, essa afirmação tornar-se-ia inválida ou exagerada. No entanto, o trabalho com avaliação vem a reboque do trabalho com o ensino-aprendizagem (FIDALGO, 2002b, 2006, 2011a). Muito se tem pesquisado e discutido em relação ao ensino e muitas mudanças são propostas em relação a como devem ser ensinados os conteúdos, mas no que diz respeito à avaliação, ainda temos provas estáticas - em sua maioria conteudistas, estruturalistas (na área de línguas) - e algumas autoavaliações que parecem tentar cumprir o papel de amenizar a consciência dos proponentes, mas pouco ou nada mudam em relação à atividade avaliativa de fato ou à atribuição de notas ao final do processo.

Nos últimos tempos, tem havido muita discussão sobre avaliação (AFONSO, 2000; PORTILHO; ALMEIDA, 2008; ANDRIOLA, 2012; SORDI; LUDKE, 2009) o que demonstra a crescente preocupação com o tema. Como afirmam Sordi e Ludke (2009), há uma gama de interesses e valores que regem o processo avaliativo nas escolas, o que resulta - ou deveria - em uma necessidade de negociação para um trabalho eficaz no que diz respeito à avaliação. No entanto, o que vemos são trabalhos educacionais díspares pautados por crenças individuais de professores que acreditam ser preciso reprovar um determinado número de alunos para que eles "deem valor à disciplina e respeitem o professor", ao passo que outros acreditam que é preciso desenvolver a capacidade do aluno se autoavaliar e de "se tornar mais crítico". No segundo caso, a autoavaliação é percebida como uma técnica que consiste em pedir ao aluno que valorize o próprio trabalho ou a capacidade para exercer uma tarefa pedagógica. Parece demonstrar uma prática democrática "em nome do não controle, da não arbitrariedade, da não classificação” (RABELO, 1998, p. 79). Assim, enquanto muitos utilizam a avaliação como punição ou ameaça, outros admitem uma visão de que a avaliação deve conduzir as atividades de ensinoaprendizagem.

Sabe-se que, por meio da avaliação, pode-se modificar o currículo em um processo que teoricamente se conhece como efeito retroativo (backwash effect), que se refere à consequência dos resultados obtidos ou esperados em provas e testes sobre o ensino ou sobre a prática educativa. Um dos efeitos da 
validade de refluxo no ensino é o que Luckesi (1994) chama de pedagogia do exame. Para o autor, essa pedagogia faz com que a comunidade escolar volte o olhar para a docimologia ${ }^{1}$ e isto, por sua vez, influencia a educação a ponto de fazer com que professores preparem alunos para passar em exames e não para a vida.

Levando em consideração o debate sobre os tipos de avaliações praticados, buscamos, com este trabalho, analisar documentos curriculares de seis estados brasileiros (Acre, Alagoas, Mato Grosso, Paraná, Pernambuco e São Paulo) no que diz respeito ao ensino de Língua Estrangeira - no caso, o idioma inglês para verificar a avaliação de aprendizagem sugerida pelos elaboradores desses materiais.

A escolha de objetivo para este trabalho se deve a uma preocupação mais geral acerca de avaliação, já demonstrada em outros textos (FIDALGO, 2002a; 2002b; 2004; 2005a; 2005b), nos quais discutimos os instrumentos usados em avaliação, verificando quais podem servir ao propósito de auxiliar o aluno a refletir sobre sua aprendizagem com a ajuda de seus pares e do professor, possibilitando, assim, uma regulação interativa, permitindo uma intervenção didática (Cf. PERRENOUD, 1998) - e que, portanto, seja parte do processo de ensino-aprendizagem e não dissociada dele.

Para descrever o processo de análise seguido, dividiremos este trabalho nas seguintes partes: (1) a terminologia usada em avaliação; (2) a descrição do instrumento e o contexto de análise; (3) as avaliações em materiais oficiais; (4) considerações.

\section{O PROCESSO AVALIATIVO, SEUS SIGNIFICADOS E SUA CONSTRUÇÃO}

Neste tópico será realizada uma breve discussão sobre alguns tipos de avaliação - mais para distingui-las e esclarecer suas funções. Os termos mais comumente utilizados no Brasil talvez sejam a avaliação formativa e a qualitativa - essa última, mantendo a ligação que a avaliação parece ter com a área de metodologia de pesquisa (cf. FIDALGO, 2002a). A avaliação formativa opõe-se à avaliação somativa - preocupada com o controle, com resultados e produtos adquiridos (BONNIOL, 1989). Também se opõe à avaliação normativa, comprometida com a hierarquização de alunos por seus resultados e muitas

Termo utilizado por Henri Piéron em 1920. Trata-se do estudo sistemático dos exames, em particular do sistema de atribuição de notas e dos comportamentos dos examinadores e examinados. Disponível em: 〈https://pt.wikipedia.org/wiki/Docimologia〉. Acesso em: 16 maio 2016. 
vezes por seu nível social. 0 termo avaliação qualitativa, embora diferente em terminologia, se opõe à quantitativa pelos mesmos motivos, além de seguir também uma terminologia da área de pesquisa - terminologia esta que é muito comum em avaliação.

Em texto anterior, Fidalgo (2007) defende que a discussão sobre o uso da terminologia formativa ou qualitativa se deve à centralidade na ação do aluno (formativa) ou do professor (qualitativa), com base nos documentos que as defendem (como os PCN - documento de Introdução, 1997, p. 52), por exemplo, que, ao falar de uma interpretação “qualitativa”, define-a como “[...] um conjunto de atuações que tem a função de alimentar, sustentar e orientar a intervenção pedagógica”, colocando a centralidade de sua ação claramente no professor. Já Perrenoud (1998) classifica a avaliação formativa como estando a serviço da aprendizagem. Como acreditamos que a avaliação deve ser uma ação conjunta de professores e alunos (inclusive em avaliação de pares, em que os alunos se avaliam uns aos outros com o intuito de [1] aprender a se autoavaliar e [2] atribuir uma nota ao colega ao mesmo tempo que se proveem sugestões de aprendizagem), defendemos que talvez fosse o caso de se pensar em usar formativo-qualitativa, distribuindo, assim, a responsabilidade entre todos os agentes. Aceitar que a função da avaliação é ser formativo-qualitativa é não priorizar nem o que é ensinado apenas (conteúdos), como acontece na avaliação bancária² (ROMÃO, 1998), nem somente o que é aprendido - visão desenvolvimentista da formação, - mas uma atividade de ensinar-avaliaraprender-avaliar-ensinar, espiralada e revisitada a cada ação; desconstruída e reconstruída como parte do processo de desenvolvimento de professores e alunos. Ao mesmo tempo, desconstrói a avaliação normativa - que hierarquicamente inclui alguns alunos à medida que exclui outros, já que seu objetivo é verificar o rendimento alcançado por um aluno em comparação com os demais do mesmo grupo. A avaliação normativa, entretanto, assume várias formas $^{3}$ e, sendo acolhida pela sociedade, torna-se mais difícil de superar. No ensino de Língua Estrangeira, um dos formatos mais comuns é a prova de língua per se, sem evidência de sua aplicabilidade na vida do aluno.

Com base na metáfora da Educação Bancária de Freire, Romão (1998) utiliza o termo avaliação bancária que teria o objetivo de obter do aluno os depósitos realizados pelo professor. Fidalgo (2006) acrescenta que esses depósitos não podem ser acrescidos de juros ou sofrer deduções, já que os conteúdos devem ser devolvidos para o professor exatamente como foram depositados.

É utilizada em exames, como o vestibular, por exemplo, e em competições de vários tipos, ganhando espaço nas salas de aula, estimulando a competição e não a colaboração e a aprendizagem coletiva, ao contrário do que deveria ser. 
Por sustentar e orientar a intervenção pedagógica, a avaliação formativoqualitativa deve ser vista como parte do processo de ensino-aprendizagem, como um diagnóstico tanto para professores quanto para alunos. Partindo dessa função de diagnosticar para orientar a intervenção, é possível encontrar provas em formatos antigos (língua isolada) com roupagem (definições e funções) nova. No entanto, para que serve diagnosticar se os alunos identificam ou utilizam estruturas isoladamente, via preenchimento de lacunas infindáveis com tempos verbais, pronomes e preposições diversos? Alguns afirmam ser uma forma objetiva de avaliar. Do mesmo modo, tem sido "objetiva" a forma de ensinar por meio de listas infindáveis de adjetivos e verbos?

Outro aspecto presente quando se trata de instrumento de avaliação é a questão da objetividade/subjetividade. Pesquisas evidenciam que provas com o mesmo conteúdo ou com o mesmo objetivo, se elaboradas por professores diferentes, podem ter resultados diferentes (BONNIOL; VIAL, 2001). Isso indica que a escolha de palavras e a organização das instruções influenciam o resultado final. Logo, será que é possível haver uma prova realmente objetiva? Para Bonniol e Vial (2001), a discussão sobre objetividade/subjetividade é um debate estéril, já que toda avaliação é, no fundo, subjetiva, porque está sujeita à elaboração e correção por alguns sujeitos com poder e também com preferências, com humores, atitudes diferentes em momentos diversos.

Além de objetividade, é preciso pensar em validade quando se fala em avaliação, termo definido como o grau pelo qual as notas de um teste permitem tirar conclusões em relação ao objetivo deste. Há diversos tipos de validade; os que discutiremos a seguir são os que nos interessam neste trabalho.

- 1) Validade de construto - é uma espécie de validade conceitual. Uma avaliação tem validade de construto se pudermos demonstrar que ela mede, exatamente, o construto que deve medir (HUGHES, 1989). Considerando que este texto avalia material de Língua Inglesa, tomemos este caso como exemplo. No ensino dessa língua estrangeira, poderíamos pensar em termos das habilidades (leitura, escrita, fala e compreensão oral). Se tomarmos uma prova de compreensão oral que traga uma instrução escrita em Língua Inglesa, de difícil compreensão, teríamos um problema de validade de construto, uma vez que a prova estaria testando a compreensão escrita. Se o aluno não conseguir fazer a prova, terá sido por sua incapacidade de compreender o que foi dito ou por sua incapacidade de compreender a instrução escrita? Por outro lado, uma prova que utilize tarefas com lacunas para preenchimento de preposições, tempos verbais, etc., só terá validade de construto 
se as tarefas do curso proposto estiverem centradas na gramática da língua.

- 2) Validade de conteúdo - têm as provas cujo conteúdo apresenta uma quantidade representativa daquilo que tenha sido estudado anteriormente. Assim, uma prova cujo enfoque seja tempos verbais só terá validade de conteúdo se os mesmos tempos verbais tiverem sido estudados durante o curso. Já uma prova que pressuponha o conhecimento de tipos de texto, como algumas provas do Sistema de Avaliação de Rendimento Escolar do Estado de São Paulo (Saresp) ${ }^{4}$, por exemplo, só terá validade de conteúdo se os alunos tiverem estudado os diferentes tipos de texto, uma vez que os conteúdos cobrados deveriam ter sido estudados na trajetória do aluno 5 .

- 3) Validade aparente - é uma espécie de atração da medida avaliativa. É a "qualidade dum teste ou de qualquer medida que pareça correcta e adequada ao objecto medido" (MILANOVIC, 1998, p. 394). É, portanto, uma validação por parte dos usuários da avaliação proposta. Se a forma de avaliação proposta parecer correta aos olhos daqueles que a utilizam, então há validade aparente, ainda que sobre essa avaliação alguns educadores possam discordar. Acredita-se, por exemplo, que 0 vestibular é o exame que mede a capacidade dos alunos e a qualidade de sua formação. Se o aluno passa no vestibular ou no Exame Nacional do Ensino Médio (Enem), ele passa a ter o status de indivíduo que teve uma formação diferenciada que lhe permitiu ingressar no ensino superior. Diversos educadores debatem e discordam da utilização dessa medida avaliativa como o(s) exame(s) que dirige $(\mathrm{m})$ os planos escolares - efeito retroativo (HUGHES, 1989; WEIR, 1993; LUCKESI, 1994). Luckesi (1994) chama essa prática de docimologia, uma busca pelo estabelecimento do valor daquilo que aprendemos. No entanto, o movimento social (dos pais e alunos, principalmente) indica que o vestibular e o Enem são validados socialmente como medida do desempenho escolar.

\footnotetext{
Em vigor desde 1996.

Esse último comentário leva ao que chamamos de efeito retroativo, já que, se pensarmos bem, há escolas que passaram a trabalhar os conteúdos de modo a que o aluno possa conseguir uma boa nota no Saresp. Logo, o Saresp estaria alimentando a prática pedagógica. 0 mesmo acontece com escolas cujos conteúdos são focados no vestibular ou no Exame Nacional do Ensino Médio (Enem), por exemplo.
} 
0 presente trabalho resulta de uma pesquisa inicial realizada como membro de uma equipe contatada pelo Centro de Estudos e Pesquisas em Educação, Cultura e Ação Comunitária (Cenpec) intitulada "Currículos para os anos finais do ensino fundamental: Concepções, modos de implantação, usos”. Para realizar esse trabalho, foram analisados documentos oficiais dos estados do Acre, Alagoas, Mato Grosso, Paraná, Pernambuco e São Paulo. Foi seguida uma ficha de análise da qual constavam questões que incluíam desde a leitura da tipologia de conteúdos e como estes eram tratados até a abordagem de questões relativas à diversidade. Dos vários temas analisados, foram utilizados para 0 presente trabalho os aspectos que tratam da fundamentação dos documentos e da avaliação no conjunto de documentos dos estados supracitados.

Lembramos que o objetivo do presente trabalho é analisar documentos curriculares utilizados nos seis estados brasileiros citados no que diz respeito ao ensino de Língua Estrangeira (LE) - no caso, o idioma inglês - para discutir a avaliação de aprendizagem sugerida pelos elaboradores desses materiais.

Esta parte tem como objetivo discutir como a avaliação de aprendizagem é apresentada nos documentos curriculares de Língua Inglesa de seis estados brasileiros. 0 procedimento de análise partirá de uma breve descrição do documento quanto ao público-alvo (alunos do ensino fundamental e do ensino médio ${ }^{6}$, incluindo alunos de Educação de Jovens e Adultos [EJA], exceto em São Paulo) e questões de ensino-aprendizagem para, em seguida, trazer uma apreciação da avaliação e de seus instrumentos sugeridos, apoiando a discussão teórica em questões de validade.

O lugar da avaliação nos documentos curriculares de seis estados: teorias e instrumentos

A análise do conjunto de documentos curriculares dos seis estados investigados evidenciou que nem todos os materiais apresentam uma proposta ou discussão sobre avaliação de ensino-aprendizagem. Em Pernambuco, por exemplo, apenas no caderno Parâmetros para a Educação Básica do Estado de Pernambuco: Parâmetros Curriculares de Língua Inglesa - Educação de Jovens e Adultos (PERNAMBUCO, 2013b) encontramos uma sugestão clara com relação à avaliação formativa, seguindo os PCN de Língua Inglesa. Esse caderno menciona a importância da avaliação para "o que e como os estudantes

6 Embora o projeto se intitule "Currículos para os anos finais do ensino fundamental: concepções, modos de implantação, usos”, acabamos analisando também o material do ensino médio para que tivéssemos uma visão mais ampla da progressão dos currículos e das transições entre essas duas etapas de ensino. 
aprendem ou deixam de aprender”. Os autores defendem que a avaliação deve ser "multidimensional, voltada para os vários fatores que perpassam o processo de ensino-aprendizagem [...]" (PERNAMBUCO, 2013b, p. 23). Dessa forma, estão de acordo com as teorias mais atuais sobre o tema de avaliação.

Já o documento do Acre apresenta bastante discussão sobre a avaliação de ensino-aprendizagem. Todos os cadernos, inclusive o de EJA, falam em avaliação, sugerindo ser este um tema importante para o estado. No material da EJA, dos 31 livros citados nas referências bibliográficas, nove são sobre avaliação; os cadernos (de ensino fundamental e médio) tratam do tema das páginas 16-19 e ainda separam uma das quatro colunas do currículo para orientar o professor sobre como poderia avaliar cada um dos objetivos, sugerindo mais de uma possibilidade de avaliação para cada objetivo. Os autores citam formas que o professor pode usar para avaliar o aluno e outras que ele pode usar para que o grupo avalie o colega, seguindo, portanto, uma perspectiva mais dinâmica e formativa de avaliação, que inclui triangulação de dados avaliativos (dois tipos de alter-avaliação: a avaliação pelo professor e a avaliação de pares e uma autoavaliação). Segundo Fidalgo (2011b), toda autoavaliação (realizada pelo próprio agente, no caso, o aluno, com respeito à sua aprendizagem) é ensinada-aprendida em ações de alter-avaliação (avaliação pelo outro). A alteravaliação é uma atividade bastante antiga em nossa cultura; todos avaliamos uns aos outros desde o momento em que nos olhamos. 0 aluno aprende a se autoavaliar pelas avaliações que dele fazem os outros (professores e colegas), de forma mais inclusiva ou excludente - dependendo de cada sala de aula e das ações docentes.

A ideia de incluir alter e autoavaliações é, sem dúvida, mais formativa e sóciohistórico-cultural do que uma avaliação em forma de prova realizada apenas pelo professor ao final do ano letivo ou de cada bimestre. Além disso, os autores sugerem avaliar o aluno em relação a ele mesmo antes do trabalho pedagógico realizado pelo professor e comparar esse nível de conhecimento com o que ele demonstra ter adquirido no processo.

Embora não seja denominada explicitamente de zona de desenvolvimento proximal (ZDP), a proposta acreana de avaliação parece se aproximar bastante do conceito vygotskiano, ou seja, é uma avaliação que se faz sobre o que o aluno ainda está aprendendo e sobre o que ele consegue internalizar durante 0 curso do ensino-aprendizagem durante o período de intervenção pedagógica. Não defendem os autores uma avaliação estática - realizada por provas de língua fixas e sem vida. Defendem avaliações do processo de aprendizagem pelos próprios aprendizes e por seus pares (aqui incluído o professor). 
Nesse estado, encontramos ainda um caderno que reserva uma seção especificamente para esse tema (ACRE, 2009g) e em todos os Cadernos, de todos os anos escolares, há uma seção específica sobre o tema da avaliação de ensino-aprendizagem. O leitor é informado, por exemplo, de que, para os autores dos documentos estaduais

[...] qualquer atividade planejada especificamente para avaliar deve ser semelhante à que a criança conhece, isto é, não deve se diferenciar, na forma, das situações de ensino e aprendizagem propostas no cotidiano [...] Não faz sentido, por exemplo, avaliar o entendimento dos textos com questões de responder ou completar se no cotidiano elas são de múltipla escolha e vice-versa (ACRE, 2009g, p. 19).

Se essa orientação não for seguida, teremos um problema de validade aparente - já que é evidente que a avaliação não verificará o que foi ensinado (é aparente) - e de conteúdo - uma vez que o conteúdo está organizado de forma diversa no ensinar e no avaliar.

Sugere-se ainda, nesse estado, que as avaliações sejam de três formas: observação sistemática (acompanhamento do percurso); análise das produções e análise do desempenho em atividades específicas (ACRE, 2009g, p. 19-20), constituindo-se, assim, em uma triangulação de instrumentos avaliativos.

Há ainda uma triangulação avaliativa quando os alunos são avaliados pelo professor, por seus pares e por eles próprios (alter e autoavaliação). São feitas sugestões, em cada caderno de cada ano letivo, sobre como essas avaliações podem ocorrer, como é possível ver nos exemplos abaixo, retirados do Caderno do 5ำ ano (ACRE, 2009g, p. 27-28):

Pelo professor: Observação e levantamento dos conhecimentos prévios de cada criança em relação à fala è̀ escuta; [...]

Pela criança: Reflexão sobre o próprio processo de aprendizagem e sobre a participação no processo de avaliação a partir do preenchimento de campo específico da mesma ficha utilizada pelo professor e discussão conjunta;

Pelo grupo: Monitoramento permanente dos avanços alcançados quanto ao aprimoramento dos intercâmbios comunicativos a partir da análise das fichas preenchidas. [...]

Exemplos das fichas a serem preenchidas não são fornecidos para os professores, mas é fornecida uma lista de formas de avaliar, com suas vantagens e desvantagens, uma tabela de como elaborar uma prova e uma tabela do que deve ser avaliado.

Apesar de tudo isso, a discussão sobre a avaliação de ensino-aprendizagem, no estado do Acre, deixa a desejar nos exemplos. Na parte mais prática (as 
tabelas de como elaborar as provas e do que avaliar), o documento volta-se para “mais do mesmo", sugerindo, por exemplo, que as provas sejam divididas em três níveis, sendo o primeiro de "questões objetivas". Voltamos para a discussão do que seria a objetividade, principalmente em ensino de línguas. Se pensarmos bem, na prática, a objetividade se concretiza, muitas vezes, em questões de múltipla escolha gramaticais e lexicais, ou de preenchimento de lacunas - sempre questões com uma única resposta possível, o que limita o aluno (1) na demonstração de todo o seu conhecimento linguístico; (2) reflete um ponto de vista sobre suas escolhas linguísticas, o que, em última instância, seria muito mais representativo de sua aprendizagem do que o preenchimento de uma lacuna estática; (3) interação social com a língua que está aprendendo. Em outras palavras, na avaliação, a teoria de ensino-aprendizagem ainda é a mais tradicional, uma teoria estrutural no que diz respeito ao estudo linguístico e uma teoria fragmentada no que diz respeito ao ensino propriamente dito.

Há problemas também com os outros instrumentos: sugere-se que o professor peça ao aluno que reflita sobre a sua aprendizagem (como forma de autoavaliação). É muito positiva a autoavaliação, mas é muito difícil efetivála sem que se transforme em três itens: aprendi, talvez tenha aprendido, não aprendi (ou algo nesse sentido) em uma ficha que o aluno marcará sem fazer muito sentido do que está assinalando. Na realidade, a autoavaliação é um exercício delicado desenvolvido a partir da alter-avaliação; ou seja, os alunos vão construindo concepções de si mesmos por meio da relação entre esses dois tipos de avaliação. Não basta pedir que reflitam sobre sua aprendizagem. Não é automático.

Os documentos também sugerem o uso de portfólio - instrumento que auxilia no processo de autoavaliação, pois pode servir de base para que o aluno se veja, analise o seu histórico e crescimento, antes de se atribuir uma nota. No entanto, também o portfólio é preciso saber fazer. Não há nos documentos analisados um exemplo ou instruções de como elaborá-lo, deixando a pesquisa sobre isso, portanto, por conta do próprio professor.

Já o documento de Alagoas baseia-se em Zabala (1998) para discutir esse tema; portanto, também tem uma perspectiva formativa - embora não sócio-históricocultural - de avaliação. Os autores dizem que "O processo avaliativo deve ser contínuo, cumulativo e individual de modo que o julgamento da aprendizagem tome como referência os padrões de qualidade propostos e o desempenho escolar do educando" (ALAGOAS, 2010, p. 69). 
O documento Organização da educação básica Alagoas (ALAGOAS, 2011, p. 6) cita o primeiro parágrafo, artigo 47 da Resolução n. 4 do Conselho Nacional da Educação (Brasil, MEC, 2010), quando esta diz que

A função diagnóstica da avaliação possibilita ao estudante recriar, refazer o que aprendeu, criar, propor, apontando para uma avaliação global que vai além do aspecto quantitativo, pois identifica o desenvolvimento da autonomia do estudante, que é indissociavelmente ético, social, intelectual.

No entanto, pelo que é possível verificar na documentação analisada, são apresentadas diversas leis, códigos, resoluções, talvez para manter o professor informado de seus deveres e direitos, mas não há uma discussão sobre o ato de avaliar. Há, na realidade, determinações, como a que se segue:

A Sistemática de Avaliação da Aprendizagem da Rede Estadual de Ensino determina que a avaliação somativa seja computada semestralmente, através da aplicação de pelo menos 4 (quatro) instrumentos avaliativos com a mesma atribuição de pontos no semestre, totalizando até 40 pontos no $1^{\circ}$ semestre e até 60 pontos no $2^{\circ}$ semestre, possibilitando um Resultado Anual

(RA) de até 100 pontos por componente curricular. (ALAGOAS, 2012, p. 21, grifo nosso).

O documento de Mato Grosso utiliza os estudos de Luckesi (2005) para embasar sua discussão teórica. 0 texto do governo desse estado é para "a escola única de Educação Básica [que] propiciará uma sólida formação geral inicial que proporcionará à criança e ao jovem um desenvolvimento amplo e harmonioso que lhes confia a capacidade de atuar intelectual e praticamente" (MATO GROSSO, 2012, p. 22).

Apesar de citar Luckesi, a avaliação quase não é debatida; é tratada em termos mais gerais, no documento teórico da Secretaria de Educação de Mato Grosso e, assim mesmo, apenas em dois parágrafos. No documento sobre linguagens da Secretaria (MATO GROSSO, 2008-2010a), a avaliação é tratada em três parágrafos que salientam que é preciso evitar avaliações punitivas e incentivar as avaliações formativas. Não podemos, portanto, dizer que esse tema é um dos carros-chefes da documentação do estado de Mato Grosso.

O mesmo pode ser dito sobre o estado de São Paulo, que não evidencia a avaliação como um de seus temas principais para discussão. Não é defendida uma concepção de avaliação. Ao final de um número de Situações de Aprendizagem, há uma proposta de redação - que será, na maioria dos casos, utilizada pelos professores como uma forma de avaliação. É importante lembrar que, nos Cadernos, as Situações de Aprendizagem não enfocam, via de regra, a escrita e sim a leitura, o léxico, a gramática e até a linguagem oral, mas não a 
escrita, ou seja, não se ensina a fazer uma redação, mas se cobra uma redação ao final do processo, o que faz com que essa avaliação tenha um problema de validade de construto.

Há ainda a seção $O$ que aprendi?, em que o aluno deverá listar o que ele considera ter aprendido. É um tipo de autoavaliação melhor do que aquelas que têm as três opções, das quais o aluno deve selecionar uma, porque se o aluno tem que fazer uma lista, ele terá de se lembrar do que fez, ao passo que, se tiver que marcar simplesmente, pode escolher uma opção, sem refletir sobre ela, invalidando todo o processo da autoavaliação. No entanto, ao ter de listar contando simplesmente com a memória, o aluno está realizando um tipo de avaliação que Perrenoud (1998, p. 95) chamou de retroativa (ou pela falta). Dificilmente o aluno se lembrará de tudo o que aprendeu e saberá diferenciar o que foi internalizado (aprendido) do que viu na aula, mas não aprendeu. Ele precisa de instrumentos que o ajudem a visualizar e diferenciar (FIDALGO, 2002a) para que essa avaliação realmente aconteça.

Ao final dos Cadernos, o aluno encontra uma lista de Can do Statements ${ }^{7}$, que os autores chamaram de competências e habilidades, mas na realidade, nem todos são competências e habilidades. Alguns são simplesmente itens gramaticais: Reconhecer usos do present simple e suas estruturas; Reconhecer os usos da expressão there to be, por exemplo (Caderno da $6^{\underline{a}}$ série $/ 7^{0}$ ano). Essa listagem é seguida de mais uma oportunidade para o aluno enumerar o que aprendeu, o que ele provavelmente fará copiando da própria listagem já apresentada nos Can do Statements - e pode ou não refletir sobre o que aprendeu, dependendo de como essa tarefa for desenvolvida pelo professor.

Já o estado do Paraná utiliza o material de avaliação do Ministério da Educação (MEC), publicado em $2007^{8}$. É um caderno só sobre avaliação e é um material que serve para a formação de professores, pois traz reflexões sobre o uso de autoavaliação, sobre o uso do Conselho de Classe como um momento de aprendizagem, dentre outros temas. É um documento que se baseia em muitos autores que adotam uma postura humanista, portanto, centrada no aluno, sobre a avaliação. Em 2008, no documento Diretrizes Curriculares da Educação

No Common European Framework of Reference (CEFR), os enunciados em formato de "can do" referem-se ao que os alunos podem fazer. São enunciados que compõem a Escala Global (os níveis estabelecidos pelo (EFR) e, portanto, são usados para estabelecer os diferentes níveis de proficiência. São chamados de "can do" porque cada um deles é iniciado pelo verbo "can" (tradução livre). Disponível em: 〈https://languagetestingum. wikispaces.com/\%E2\%80\%9CCan+do\%E2\%80\%9D+Statements>. Acesso em: 20 de abr. 2016).

8 Indagações sobre currículo: Avaliação e Currículo. 
Básica, o estado do Paraná usou a concepção dialógica de avaliação (PARANÁ, 2008, p. 69). Dizem os autores:

No processo educativo, a avaliação deve se fazer presente, tanto como meio de diagnóstico do processo ensino-aprendizagem quanto como instrumento de investigação da prática pedagógica. Assim a avaliação assume uma dimensão formadora, uma vez que o fim desse processo é a aprendizagem, ou a verificação dela, mas também permitir que haja uma reflexão sobre a ação da prática pedagógica. Para cumprir essa função, a avaliação deve possibilitar o trabalho com o novo, numa dimensão criadora e criativa que envolva o ensino e a aprendizagem. Desta forma, se estabelecerá o verdadeiro sentido da avaliação: acompanhar o desempenho no presente, orientar as possibilidades de desempenho futuro e mudar as práticas insuficientes, apontando novos caminhos para superar problemas e fazer emergir novas práticas educativas (PARANÁ, 2008, p. 31).

O material trata da característica processual da avaliação, defendendo que esta não pode ser simplesmente "a mediação de competências e habilidades que um estudante exibe ao final de um determinado período ou processo de aprendizagem" para que não se torne simplesmente uma verificação do conteúdo ensinado. 0 documento também ressalta a importância do tempo na avaliação, salientando que "os resultados advindos da aplicação dos instrumentos são provisórios e não definitivos. 0 que o estudante demonstrou não conhecer em um momento poderá vir a conhecer em outro" (PARANÁ, 2008, p. 28).

Além disso, os autores afirmam que "a simples utilização de instrumentos diferenciados de provas e testes (memorial, portfólio, caderno de aprendizagens, etc.)" já garante "uma vivência de avaliação distinta da tradicional” (PARANÁ, 2008, p. 28) e apresentam uma descrição desses instrumentos no mesmo documento, o que demonstra uma preocupação com a formação docente, além de uma preocupação com o fornecimento de material legal-administrativo para os professores ou material para os alunos. Todos os esforços que levem a um desenvolvimento no processo educativo têm o seu valor, é inegável. No entanto, pensamos que, se os governos se preocuparem em fornecer material para os professores, a educação terá resultados positivos de mais longo alcance, uma vez que essa formação docente será revertida em formação discente de maior qualidade. Logo, os materiais que precisam ser implementados na avaliação poderão ser desenvolvidos pelos professores quando estes souberem como fazê-lo. 0 professor bem formado saberá como avaliar e como construir instrumentos que condigam com as necessidades dos alunos. 
No material analisado há uma discussão teórica bastante interessante sobre avaliação. No entanto, ocorre o que vimos também em outros materiais: na prática, não há exemplos para o professor sobre como fazer. Há uma descrição do que seja um portfólio e uma autoavaliação, por exemplo, mas não há informações de como elaborar uma ficha de autoavaliação que esteja coerente com os princípios defendidos nos documentos da Secretaria de Educação do estado. Essa discussão não apareceu em nenhum dos documentos analisados. Logo, cabe sempre ao professor transformar a teoria em prática na hora de avaliar - o que é bastante desafiador, já que a teoria em si não é fácil de compreender e aplicar.

\section{CONSIDERAÇÕES}

Ao contrário do que poderíamos perceber alguns anos atrás (FIDALGO, 2007), as instruções relativas à avaliação de ensino-aprendizagem hoje já não priorizam apenas as provas, indicando avanços nesse sentido. A maioria dos documentos analisados sugere que os professores realizem autoavaliações com seus alunos. Infelizmente, no entanto, ainda são autoavaliações fadadas a questionamentos relativos à validade aparente, ou seja, que dificilmente serão validadas pelos usuários e pela comunidade escolar (pais, alunos e muitos professores), pois não apresentam evidências de aprendizagem. Os professores têm dificuldades para desenvolver instrumentos de avaliação nesses moldes que estejam conectados a (ou que sejam eles mesmos) evidências de ensino-aprendizagem. Os materiais analisados também não ensinam, sequer discutem esse aspecto das autoavaliações.

Logo, muitos professores ainda podem sentir necessidade de elaborar provas tradicionais - em sua maioria de língua per se, ou seja, gramaticais e lexicais, em se tratando do ensino de Língua Inglesa. Por outro lado, é estranho que mesmo defensores de teorias tão pouco tradicionais, como é possível ver nos materiais analisados - alguns defendem um ensino mais humanista, outros um ensino sócio-histórico-cultural -, possam negligenciar a avaliação. Talvez, como os professores, também os elaboradores desses materiais ficaram de fora da discussão acerca de avaliação. Talvez falte a todos uma maior reflexão sobre por que e para que avaliar. Talvez seja mais fácil elaborar uma prova como instrumento sistêmico. Mas o que estariam provando sobre nossa capacidade de incluir pessoas em um mundo de excluídos? O que realmente estaríamos ensinando-aprendendo com instrumentos de língua vistos como unidades isoladas, se não é assim que nos comunicamos? Será que buscamos manter o ensino-avaliação-aprendizagem como forma neutra de agir e, por isso, ainda 
avaliamos língua isolada? Será que não queremos professores que sejam capazes de mudar o status quo da educação, a começar pela sua capacidade de avaliar a sua ação e a de seus alunos, o ensino-aprendizagem que ocorre (ou pode ocorrer) dialeticamente em sua sala de aula? Ficam questionamentos e fica uma reflexão de Giroux (1997, p. 1):

Para que os professores e outros se engajem em tal debate, é necessário que uma perspectiva teórica seja desenvolvida, redefinindo a natureza da crise educacional e ao mesmo tempo fornecendo as bases para uma visão alternativa para a formação e trabalho dos professores.

Em resumo, o reconhecimento de que a atual crise na educação tem muito a ver com a tendência crescente de enfraquecimento dos professores em todos os níveis da educação é uma precondição teórica necessária para que eles efetivamente se organizem e estabeleçam uma voz coletiva no debate atual. Além disso, tal reconhecimento terá que enfrentar não apenas a crescente perda de poder entre os professores em torno das condições de seu trabalho, mas também as mudanças na percepção do público quanto a seu papel de praticantes reflexivos. 


\section{Teaching-Learning Assessment and State Public Policies: A Theoretical- Practical Review}

Abstract: This article results from an analysis of proposals of assessment found in curricular documents of the late years of primary school in the discipline of English in six Brazilian states. Its goal is to discuss the relationship between the assessments proposed and the teaching-learning goals expressed in the documents. We found that, although there are texts in these documents that claim to follow a socio-historical-cultural proposal (based on Vygotsky's work from 1926 to 1934), their evaluation proposals seldom follow the same perspective. We also found that the instructions concerning teaching-learning assessment do not prioritize only tests, but also include self-evaluation.

Keywords: Teaching-learning assessment, apparent validity, construct validity, content validity, teaching-learning theories. 


\section{La evaluación de la enseñanza-aprendizaje y las políticas públicas estatales: una revisión teórico-práctica}

Resumen: El presente artículo es el resultado del análisis de las propuestas de evaluación de los documentos curriculares de enseñanza fundamental 2 en la asignatura de Inglés de seis estados brasileños. Su objetivo es discutir la relación entre las evaluaciones propuestas y los objetos de enseñanza-aprendizaje expresados en esos documentos. Se concluye que, aunque encontremos en ellos textos que afirman seguir una propuesta sociohistórico-cultural (con base en Vygotsky, 1926 a 1934), su propuesta de evaluación, por lo general, aún no sigue la misma perspectiva. Se verifica también que las instrucciones relativas a la evaluación de la enseñanza-aprendizaje no priorizan solamente los exámenes, sino que también incluyen la autoevaluación.

Palabras clave: Evaluación de enseñanza-aprendizaje. Validez aparente. Validez de constructo. Validez de contenido. Teorías de enseñanza-aprendizaje. 


\section{REFERÊNCIAS}

ACRE (Estado). SEE. Coordenação de Educação de Jovens e Adultos. A política e a organização da educação de jovens e adultos no Acre. Rio Branco: Secretaria de Estado de Educação, 2008.

Planejamento escolar: compromisso com a aprendizagem. Rio Branco: Secretaria de Estado de Educação, 2009a.

. Para organizar o trabalho pedagógico do ensino fundamental. Caderno 2 - Geral. Rio Branco: Secretaria de Estado de Educação; Secretaria Municipal de Educação, 2009b.

Orientações curriculares para o ciclo inicial. $2^{\circ}$ ano - volume 2 . Rio Branco: Secretaria de Estado de Educação; Secretaria Municipal de Educação, 2009c.

Orientações curriculares para o ciclo inicial. $1^{0}$ ano - volume 2. Rio Branco: Secretaria de Estado de Educação; Secretaria Municipal de Educação, 2009d.

Orientações curriculares para o ensino fundamental. Caderno $1-4^{\circ}$ ano. Rio Branco: Secretaria de Estado de Educação; Secretaria Municipal de Educação, 2009e.

Orientações curriculares para o ensino fundamental. Caderno 1 - $3^{\circ}$ ano. Rio Branco: Secretaria de Estado de Educação; Secretaria Municipal de Educação, 2009f.

Orientações curriculares para o ensino fundamental. Caderno $1-5^{0}$ ano. Rio Branco: Secretaria de Estado de Educação; Secretaria Municipal de Educação, 2009g.

Orientações curriculares para o ensino fundamental. - Caderno 1 Língua Inglesa. Rio Branco: Secretaria de Estado de Educação, 2010a.

Orientações curriculares para o ensino médio - Caderno 1 - Língua Inglesa. Rio Branco: Secretaria de Estado de Educação, 2010b.

AFONSO, A. J. Avaliação educacional: regulação e emancipação. São Paulo: Cortez, 2000.

ANDRIOLA, W. B. A avaliação do aprendizado discente: estudo com professores 
de escolas públicas. Educação em Revista, Curitiba, n. 46, out./dez. 2012, p. 141-158.

ALAGOAS. SEE. Referencial curricular da educação básica para as escolas públicas de Alagoas. Alagoas: Secretaria do Estado de Educação e do Esporte, 2010.

Superintendência de Políticas Educacionais. Diretoria de Educação Básica. Orientações para matrícula, enturmação, organização curricular e avaliação. Alagoas: Secretaria do Estado de Educação e do Esporte, 2010.

Orientações para organização do ensino fundamental. Alagoas:

Secretaria do Estado de Educação e do Esporte, 2012

BACHMAN, L. F. Fundamental considerations in language testing. Oxford: Oxford University Press, 1990.

BAKHTIN, M. [Volochínov, V. N.] 0 freudismo. Tradução Paulo Bezerra. São Paulo: Perspectiva, 1927/2001.

- Marxismo e filosofia da linguagem. Tradução Michel Lahud e Yara

Frateschi Vieira. São Paulo: Hucitec, 1929/1999.

BONNIOL, J. J. Entre les deux logiques de l'évaluation en psychologie: approches théoriques et conditions méthodologiques. AECSE, n. 6, p.12-18, 1989.

; VIAL, M. Modelos de avaliação: textos fundamentais. Tradução Cláudia Schilling. Porto Alegre: Artmed, 2001.

BRASIL. Secretaria de Ensino Fundamental. Parâmetros Curriculares Nacionais: introdução. Brasília: MEC/SEF, 1997/2000.

Parâmetros Curriculares Nacionais: terceiro e quarto ciclos do ensino fundamental - Língua Estrangeira. Brasília: MEC/SEF, 1998.

Orientações Curriculares para o Ensino Médio - v. 1 - Linguagens, Códigos e suas Tecnologias. Brasília: MEC/SEB, 2006.

. Secretaria de Educação Básica. Indagações sobre currículo: currículo e avaliação. Brasília: MEC/SEB, 2007.

BRASIL. MINISTÉRIO DA EDUCAÇÃO CONSELHO NACIONAL DE EDUCAÇÃO C MARA DE EDUCAÇÃO BÁSICA. Resolução no 4, de 13 de julho de 2010. Brasília: MEC, 2010. 
DOLZ, J.; NOVERRAZ, M.; SCHNEUWLY, B. Sequências didáticas para o oral e a escrita: apresentação de um procedimento. In: SCHNEUWLY, B.; DOLZ, J. Gêneros orais e escritos na escola. Tradução Roxane Rojo, Glaís Sales Cordeiro. Campinas: Mercado de Letras. 2004. p. 95-128.

FAZENDA, J. C. A. Integração e interdiscipinaridade no ensino brasileiro: efetividade ou ideologia. 5. ed. São Paulo: Loyola, 2002.

FIDALGO, S. S. Avaliação de ensino-aprendizagem: ferramenta para a formação de agentes críticos. 2002. Dissertação (Mestrado em Linguística Aplicada e Estudos da Linguagem)-Pontifícia Universidade Católica de São Paulo, São Paulo, 2002a.

Aprendendo a ensinar, a avaliar. Intercâmbio, Lael-PUC/SP, v. XI, p. 117-124, 2002b.

A avaliação de aprendizagem em livros didáticos de inglês. Revista Contexturas. São Paulo, Apliesp, v.7, p. 9-24, 2004.

Há que se pensar as teorias de ensino-aprendizagem, mas sem negligenciar a avaliação. In: CBLA, 7, 2005, São Paulo. Anais... São Paulo, PUCSP, 2005a.

. Auto-avaliação: uma questão de prática? Ou de representações? The ESPecialist. São Paulo, PUC-SP, v. 26, p. 137-154, 2005b.

. A avaliação na escola: um histórico de exclusão social-escolar ou uma proposta sociocultural para inclusão? Revista Brasileira de Linguística Aplicada, Belo Horizonte, UFMG, v. 6, s. 2, p. 16-32, 2006.

- Livros didáticos e avaliação de aprendizagem: uma revisão teóricoprática. In: DAMIANOVIC, M. C. Material didático: elaboração e avaliação. Taubaté: Unitau, 2007. p. 287-318.

Ensino de língua e avaliação de ensino-aprendizagem: uma possibilidade na perspectiva sócio-histórico-cultural. Ângulo, Lorena, Fatea, v. 123, s. 1, p. 93-101, 2010.

Por uma linguagem como objeto-instrumento de avaliações inclusivas. In: SILVEIRA, E. M. As bordas da linguagem. Uberlândia: UFU, 2011a. p. 319335.

Avaliação em língua estrangeira. In. LIBERALI, F. C. A reflexão e a 
prática no ensino - v. 2 - inglês. São Paulo: Edgard Blücher, 2011b. p. 157-171. GIROUX, H. A. Os professores como intelectuais: rumo a uma pedagogia crítica da aprendizagem. Porto Alegre: Artes Médicas, 1997. 270 p.

HOLQUIST, M. Dialogism: Bakhtin and his world. London: Routledge, 1990.

HUGHES, A. Testing for language teachers. Cambridge: Cambridge University Press, 1989.

KERN, R. Literacy and language teaching. Oxford: Oxford University Press, 2000.

KLEIMAN, A. Oficina de leitura: teoria e prática. Campinas: Pontes, 2002.

KRAMSCH, C. Social discursive constructions of self in L2 learning. In: LANTOLF, J. Sociocultural theory and second language learning. Oxford: Oxford University Press. 2000. p. 133-154.

LADO, R. Language teaching: a scientific approach. New York: McGraw-Hill, 1964.

LANTOLF, J. Sociocultural theory and second language learning. Oxford: Oxford University Press, 2000.

LUCKESI, C. C. Avaliação da aprendizagem escolar. São Paulo: Cortez, 1994. Avaliação da aprendizagem... mais uma vez. Revista ABC Educatio, n. 46, p. 28-29, jun. 2005.

MATO GROSSO (Estado). SEE. Secretaria Adjunta de Políticas Educacionais. Superintendência da Educação Básica. Orientações curriculares - áreas de linguagens - educação básica. Cuiabá: Secretaria do Estado de Educação, 2008-2010a.

SEE. Superintendência da Educação Básica. Orientações curriculares concepções para a educação básica. Cuiabá: Secretaria do Estado de Educação, 2008-2010b.

. Orientações curriculares: concepções para a educação básica. Cuiabá:

Secretaria do Estado de Educação, 2012.

SEE. Superintendência da Educação Básica. Coordenadoria do Ensino Fundamental. Orientativo 2013 - Ciclos de formação humana. Cuiabá: Secretaria do Estado de Educação, 2013. 
- Orientações Curriculares para a educação básica do estado do Mato Grosso. Cuiabá: Secretaria do Estado de Educação, s/d.

SEE. Orientações curriculares das diversidades educacionais. Cuiabá: Secretaria do Estado de Educação, s/d.

MILANOVIC, M. (Ed.). Studies in Language Testing 6: Multilingual glossary of language testing terms, prepared by Alte members. Cambridge: Cambridge University Press, 1998.

PALMER, A S.; BACHMAN, L. F. Language testing in practice. Oxford: Oxford University Press, 1997.

PARANÁ. Língua Estrangeira Moderna - Espanhol e Inglês - Ensino Médio. Curitiba: Seed-PR, 2006.

. SEE. Diretrizes Curriculares da Educação Básica. Curitiba: Secretaria de Estado de Educação do Paraná, 2008.

- Departamento de Educação Básica. Caderno de Expectativas de Aprendizagem. Curitiba: Secretaria de Estado de Educação do Paraná, 2012.

PERNAMBUCO (Estado). SEE. Parâmetros curriculares para a educação básica do Estado de Pernambuco: Parâmetros na Sala de Aula - Língua Inglesa, ensino fundamental e médio. Pernambuco: Secretaria do Estado de Educação/Undime, $2013 a$.

Parâmetros curriculares para a educação básica do Estado de Pernambuco: Parâmetros Curriculares de Língua Inglesa, Educação de Jovens e Adultos. Pernambuco: Secretaria do Estado de Educação/Undime, 2013b.

Parâmetros curriculares para a educação básica do Estado de Pernambuco: Parâmetros Curriculares de Língua Inglesa, ensino fundamental e médio. Pernambuco: Secretaria do Estado de Educação/Undime, 2013c.

Parâmetros curriculares para a educação básica do Estado de Pernambuco: Parâmetros na Sala de Aula - Língua Inglesa, Educação de Jovens e Adultos. Pernambuco: Secretaria do Estado de Educação/Undime, 2013d.

Parâmetros curriculares para a educação básica do Estado de Pernambuco: Parâmetros de Formação Docente - Línguas, Artes e Educação Física. Pernambuco: Secretaria do Estado de Educação/Undime, 2013e.

Secretaria Executiva do Desenvolvimento da Educação. Proposta 
pedagógica - Centros de atendimento socioeducativo - Cases-PE. Pernambuco: Secretaria do Estado de Educação, s/d.

PERRENOUD, P. Avaliação: da excelência à regulação das aprendizagens. Entre duas lógicas. Tradução Patrícia Chittoni Ramos. Porto Alegre: Artmed, 1998.

PORTILHO, E. M. L.; ALMEIDA, S. do C. D. de. Avaliando a aprendizagem e o ensino com pesquisa no ensino médio. Ensaio: Avaliação e Políticas Públicas em Educação. Rio de Janeiro, Julho-Setembro 2008. v. 16, n. 60, p. 469-488, jul./set. 2008. Disponível em : 〈www.scielo.br〉. Acesso em: 16 jan. 2016.

RABELO, E. H. Avaliação: novos tempos, novas práticas. Petrópolis: Vozes. 1998.

ROJO, R. Pedagogia dos multiletramentos: diversidade cultural e de linguagens na escola. In: ROJO, R.; MOURA, E. (Org.). Multiletramentos na escola. São Paulo: Parábola Editorial, 2012.

; MOURA, E. (Org.). Multiletramentos na escola. São Paulo: Parábola Editorial, 2012.

ROMÃO, J. E. Avaliação dialógica: desafios e perspectivas. São Paulo: Cortez \& Instituto Paulo Freire, 1998.

SÃO PAULO (Estado). Proposta Curricular de Língua Estrangeira Moderna: Inglês $1^{\circ}$ grau. São Paulo, SEE/Cenp, 1988.

SEE. Currículo do Estado de São Paulo: Linguagens, Códigos e suas Tecnologias. Ensino Fundamental - Ciclo II - e Ensino Médio. 2. ed. São Paulo: Secretaria de Estado da Educação, 2012a.

SEE. Coordenadoria de Gestão da Educação Básica. Reorganização do ensino fundamental e médio. São Paulo: Secretaria de Estado da Educação, $2012 b$.

Material de Apoio ao Currículo do Estado de São Paulo: Caderno do Professor. Inglês. 3a série. Ensino Médio. v. 2. São Paulo: Secretaria de Estado da Educação, 2014-2017a.

Material de Apoio ao Currículo do Estado de São Paulo: Caderno do Professor. Inglês. 3a série. Ensino Médio. v. 1. São Paulo: Secretaria de Estado da Educação, 2014-2017b.

. Material de Apoio ao Currículo do Estado de São Paulo: Caderno do 
Professor. Inglês. 2a série. Ensino Médio. v. 2. São Paulo: Secretaria de Estado da Educação, 2014-2017c.

Material de Apoio ao Currículo do Estado de São Paulo: Caderno do Professor. Inglês. 2a série. Ensino Médio. v. 1. São Paulo: Secretaria de Estado da Educação, 2014-2017d.

Material de Apoio ao Currículo do Estado de São Paulo: Caderno do Professor. Inglês. 1a série. Ensino Médio. v. 2. São Paulo: Secretaria de Estado de Educação, 2014-2017e.

Material de Apoio ao Currículo do Estado de São Paulo: Caderno do Professor. Inglês. 1a série. Ensino Médio. v. 1. São Paulo: Secretaria de Estado de Educação, 2014-2017f.

Material de Apoio ao Currículo do Estado de São Paulo: Caderno do Professor. Inglês. 8a . série/9ํano. São Paulo: Secretaria de Estado de Educação, 2014-2017g.

Material de Apoio ao Currículo do Estado de São Paulo: Caderno do Professor. Inglês. $7^{\text {a }}$ série/9ํano. São Paulo: Secretaria de Estado de Educação, 2014-2017h.

Material de Apoio ao Currículo do Estado de São Paulo: Caderno do Professor. Inglês. 6a série/7ํan ano. São Paulo: Secretaria de Estado de Educação, 2014-2017i.

Material de Apoio ao Currículo do Estado de São Paulo: Caderno do Professor. Inglês. 5a série/6ํano. São Paulo: Secretaria de Estado de Educação, 2014-2017j.

SAVIANI, D. Pedagogia histórico-crítica: primeiras aproximações. São Paulo: Cortez, Autores Associados, 1991.

SEDYCIAS, J. (Org.). 0 ensino do espanhol no Brasil: passado, presente e futuro. São Paulo: Parábola Editorial, 2005.

SORDI, M. R. L. de; LUDKE, M. Da avaliação da aprendizagem à avaliação institucional: aprendizagens necessárias. Avaliação (Campinas). Sorocaba, v. 14, n. 2, jul. 2009, pp. 313-336. Disponível em: 〈www.scielo.br〉. Acesso em: 16 jan. 2016.

VYGOTSKY, L.S. A formação social da mente. Tradução José Cipolla Neto, Luís 
Silveira Menna Barreto e Solange Castro Afeche. São Paulo: Martins Fontes, 1930.

Pensamento e linguagem. Tradução Jefferson Luiz Camargo. São Paulo: Martins Fontes, 1934.

WEIR, C. Understanding \& developing language tests. Londres: Prentice Hall International, 1993.

ZABALA, A. A prática educativa: como ensinar. Porto Alegre: Artmed, 1998.

\section{Sobre a autora:}

Sueli Salles Fidalgo é doutora em Linguística Aplicada e Estudos da Linguagem pela Pontifícia Universidade Católica de São Paulo, PUC/SP e é professora adjunta da Universidade federal de São Paulo (Unifesp).

ssfidalgo@terra.com.br 